\title{
Teaching Design of Programming Course under M-learning Environment
}

\author{
Hongxia $\mathrm{Wu}^{1, \mathrm{a}}$ and Zhigang Chen ${ }^{2, \mathrm{~b}}$ * \\ ${ }^{1}$ Beijing College Finance and Commerce, Beijing, China \\ ${ }^{2}$ Beijing University of Civil Engineering and Architecture, Beijing, China \\ awuhx@bjczy.edu.cn, bgangzi22@163.com \\ * The Corresponding Author
}

\section{Keywords: Programming course; M-learning; Teaching mode; Micro-class}

\begin{abstract}
With the rapid development of internet technology, mobile communication technology and modern electronic equipment, people began to have awareness of the importance of mobile learning. Mobile learning greatly satisfies the individual learning needs of learners and people pay more attention to the teaching design in Mobile Learning Environment. Firstly, in this paper, the concept and characteristics of mobile learning are introduced. The adaptability of mobile learning was analyzed in programming courses and the main strategies and implementation of mobile learning instructional design was discussed. Analysis shows that mobile learning can be used as an auxiliary teaching method in the classroom teaching of programming.
\end{abstract}

\section{Introduction}

With the development of information technology, the teaching methods commonly used in Chinese colleges and universities are constantly challenged. In the era of accelerating knowledge renewal period, there are many shortcomings in teaching method, such as the neglect of individual students, lack of the effective interaction between teachers and students, pour teaching mode out of touch with reality, learning everything by rote and so on. Even, the teaching method of traditional classroom teaching is also referred to as restricting the development of students' thinking mode and the development of innovative abilities, seriously depressing students' enthusiasm and innovation [1]. Therefore, it is necessary to set up a teaching mode that takes students as the main body.

Mobile learning (M-Learning) is an effective way which help learners to learn according to their different purposes and different ways of learning anytime and anywhere with Mobile Internet technology, using mobile computing devices (smart phones, PDAs, mobile phones, etc.) [2]. There are several special permits for the content of mobile learning. First, mobile learning is formally mobile, meaning learners are no longer limited by time, space, and wired networks. Second, the learning environment is mobile, learning resources and learners are also mobile. Third, mobile learning is interactive in content. Finally, mobile learning is digital in its implementation. It is digital learning based on wireless mobile devices. It is developed on the basis of digital learning and is a new stage in the development of distance learning.

Nowadays, classroom teaching is the main method in most Chinese universities. Mobile learning is still in the stage of exploration and practice in China. As a new way of learning, mobile learning inevitably has an huge impact on the teaching of existing teaching. It can cause inadaptability of the original elements of education and many problems will happen. How to combine the advanced teaching idea and the technical superiority of mobile learning to realize the deep integration of mobile learning and course teaching, organically integrate mobile learning into the teaching of existing colleges and give full play to its greatest function are very worth exploring and studying. In this paper, the characteristics of mobile learning, the main strategies for instructional design, and the issues to be aware of in practice from the perspective of practical application of mobile learning were discussed. 


\section{M-Learning and Its Features}

\section{M-Learning}

The term "mobile learning" was first invented by European and American countries in the early 90s of last century and Wireless Andrew is a landmark project to begin mobile learning. Researchers have different definitions of mobile learning from different perspectives. Mobile learning can help learners break through time and space constraints to learn, to complete the established learning tasks, with the assistance of mobile devices [3]. Compared with the traditional education and teaching model, as a learning strategy in the all media era, mobile learning has the following characteristics:

No fixed place to study. Learners are not restricted by the learning sites. They can learn anytime, anywhere by using the mobile terminal device with the help of the wireless network, and can change their learning places according to their needs.

Fragmentation of learning content. Learning activities of mobile learning are generally short-term. Learners often use free time to learn a point of knowledge. Therefore, in the mobile learning design, we should consider fragmenting the learning content to adapt to the learning habits of learners with a small knowledge point at a time.

Fragmentation of learning time. Learners are also unlimited in time and can study in their fragmented time, that is, they may start to learn immediately when they can and also stop immediately.

Autonomy, personalized learning. This means that learners can decide on their own time of study, location of study, ways of learning, choice of learning content and preparation of study plans. Mobile learning can happen everywhere, it meets different learning habits and learning preferences and adapts different people with different learning abilities and levels.

Wide range of applications. Mobile learning is not only suitable for studying in school, but also for learners who have learning needs in other professional people. Anyone can study by using a mobile device at any time with the support of a wireless network. It provides people in schools and businesses with an effective tool for life-long learning.

\section{Program Design Course Features}

Program design course is a public compulsory course in non-computer majors in most universities. For non-computer majors, programming is a difficult subject and they encounter a number of problems in the actual learning process. There are many points of knowledge, concepts and functions in the course of programming, which are flexible and not easy to grasp. Students need to preview and review to have a good learning effect. However, numerous rules and confusing use make students not like learning, tired of emotions. The lack of academic and experimental teaching hours leads to difficulties to explain how to analyze and solve problems in classrooms and students programming ideas is not clear.

According to the characteristics of programming courses, it is far from to reach the purpose of teaching to make students master the course only in classroom. Therefore, the course teaching should be based on the traditional teaching methods, mobile learning methods supplemented by the teaching methods. Mobile learning is an important complement to classroom teaching to achieve an extension of classroom knowledge. In the realization of the way it can be used by the network course platform, micro-class, WeChat public number and other mobile teaching and so on.

Mobile learning is a good extra-curricular teaching method, which is an extension and supplement of classroom teaching. However, because of much temptation nowadays, it is very difficult for a student to study a course systematically in his spare time. With the popularization of smartphones, many college students play with mobile phones in classroom. According to statistics, a college student now uses mobile phones for more than 3 hours a day on average. Therefore, it is a very important research topic to how to attract students to study hard in the classroom and guide students to study after class. In this paper we don't discuss the first aspect but focus on how to attract students to learn after class. This requires a comprehensive consideration of instructional design strategies and patterns based on M-learning. 


\section{Teaching Design Principles of Program Design Course in M-learning}

As mentioned above, when combing the definition and characteristics of M-learning, it is found that some scholars view the learning activities of mobile learning as the learning activities of learning resources through mobile terminals. In fact, learning activities play a crucial role in ensuring the ultimate quality of learning. According to activity theory, learning activity is the best analysis unit in teaching design. Yang believed that learning is an external manifestation of activities. Learners achieve the learning goals through a series of teaching activities [4]. Therefore, when we pay attention to the design of M-learning, we must pay special attention to the design of mobile learning activities.

\section{Principle 1: learning Objectives Miniaturization}

The goal of mobile learning must be single, short, and independent, which is easy to implement and allows students to achieve a sense of accomplishment. Firstly, when we analyze the learning objectives of mobile learning resources, we must determine which resources to develop to help learners achieve what kind of learning objectives. Secondly, under the premise of ensuring that the learning content is relatively complete, a large knowledge point should be divided into several mini-segments for learners to learn and download. For example, the if and the switch statement are important contents of the program structure. When designing the mobile teaching content, if and switch and their conversion are taken as respectively a mobile teaching unit, so that the students can separately grasp and then comprehensively use the application. It serves the purpose of consolidation and flexible application.

\section{Principle 2: Learning Content Fragmentation}

Mobile learning is essentially a fragmented learning. The first reason is that learners often use chunks of time to conduct learning. Second, the screens for mobile learning smartphones are relatively small and cannot display a large amount of learning content at one time. For example, in the traditional class teaching, the data type may be finished in one lesson, but in the mobile learning design, the micro-objective is designed to several miniaturized teaching units according to the different data types. Only one data type is explained at a time and every learning time of each fragmented resource is controlled within 5 minutes.

\section{Principle 3: The Media is Diversified}

Mobile learners are often in informal environments such as public transportation and subways, they are easily disturbed and distracted. Therefore, mobile learning should be presented in a variety of ways, including small texts, pictures, audio or video clips, and brief descriptions. PPT, Flash, or just a link. The meaning of diversification means to use different ways to present the learning content as much as possible and use a variety of ways to attract learners for the same content segment when developing the entire process of mobile resource. For example, when teaching a cyclic structure, the use of a structure diagram or a flow chart will be beneficial to students' mastery of knowledge points. In the one-dimensional array and two-dimensional array learning, we can use the box to arrange the encoding.

\section{Principle 4: Interesting Learning Activities}

The contextualization of learning activities aims to provide learners with a joyful learning experience and enable learners to experience the fun and practicality of resource content. Programming is a very important skill for most engineers. However, the study process is often boring. Due to the miniaturization and fragmentation of mobile learning and the limitations of mobile devices, compilation and operation cannot be performed in many cases. Our design idea is to properly develop flash and other media resources that can be demonstrated and animated for miniaturized teaching content without mobile programming software. For example, when learning the application of the timer control, the key is to understand the interval. A Flash form can be designed, the speed of the action can be observed through changing the value in the text box. In addition, because most students like cartoons, some of the more boring content can be designed in cartoon form to attract students' interest in learning. 


\section{Mobile Learning Mode}

\section{Mode 1: Online Course Platform}

The online course is the sum of the teaching contents of a subject represented by the Internet and the teaching activities carried out. It consists of two components which are teaching content organized according to certain teaching strategies and network teaching environment. Among them, the network teaching environment specifically refers to the support of network teaching software tools, teaching resources and teaching activities implemented on the network teaching platform. [5]

The online course has its unique advantages. It not only overcomes the lack of time and space limitations of traditional classroom teaching, but also provides students with a personalized learning environment. In the past few years, it was often only the fine classes and excellent courses that were allowed to construct online courses. With the rapid development of network technology and hardware, more and more colleges and universities pay attention to it and began to build online courses. However, due to the lack of understanding and learning about mobile learning and online courses, many teachers just upload their own courseware, lesson plans, test papers, and other teaching materials in the online curriculum resources provided by schools. They think they complete the network course construction. They did not achieve good results. Before teachers build their courses, they must learn online course construction methods, reasonably plan the structure of network courses and the contents of teaching materials, and study the learners' extracurricular learning habits so as to attract learners to take the initiative in learning and help the classroom teaching. Figure 1 shows the general process that should be followed when designing an online course.

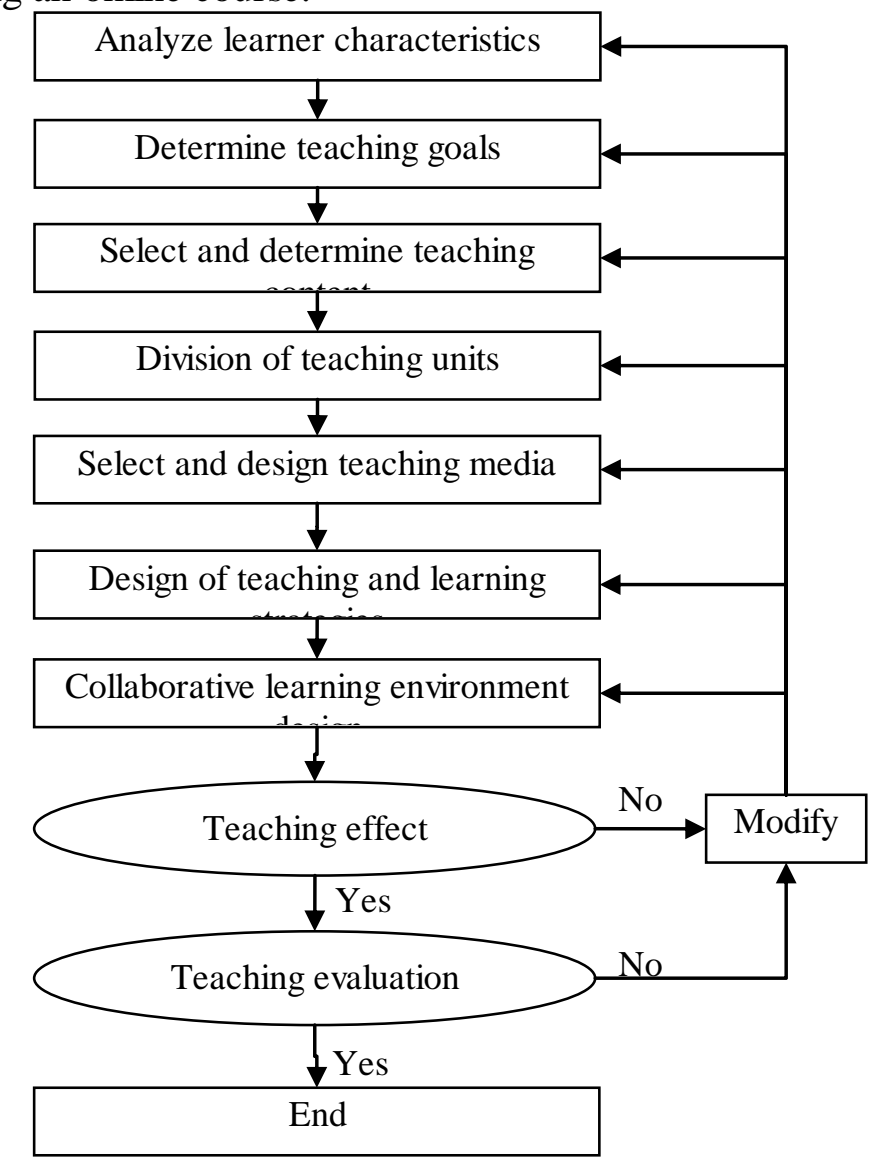

Figure.1 Design process of Mobile learning instruction

\section{Mode 2: Micro-classes}

Micro-classes are short for mobile micro-classrooms. It is a new online video course that supports multiple learning methods for a subject knowledge points (such as key, difficult, doubtful, test sites, etc.) or teaching links (such as learning activities, topics, experiments, tasks, etc.) and a contextualized design and development based on micro-teaching video as the main carrier [6]. 
Micro-classes are completely different from traditional classroom teaching mode. It has the following distinctive features. Firstly, Micro-curriculum embodies a micro feature in teaching time and teaching content. The teaching time of the micro class is generally controlled within 10 minutes, and the length of time is in accordance with the learner's effective learning time through the video of the mobile terminal. In such a short period of time, the content of the knowledge that the teacher can deliver is limited. Therefore, the micro-curriculum generally only focuses on a certain knowledge point or typical problem or example as the main teaching content. The topic of the micro-curriculum is relatively single and it is a fragmented teaching. Micro-classes are easy to watch and can be paused and played back at any time. Students can study independently and repeat learning.

\section{Mode 3: WeChat (Public Number)}

WeChat is an instant messaging service application launched by Tencent. It supports the use of cross-communication operators and cross-operating systems. The voice, video, pictures, and texts can be sent free through Internet, and streaming media content can be shared through information data. The use of WeChat in M-learning not only has a good user experience, but also provides mobile learners with more learning options and more communication methods with huge amount of users and powerful development platform [7]. WeChat public platform is a new functional module based on WeChat. Individuals and enterprises can apply for a WeChat public account to achieve full-scale communication with specific groups of text, pictures, and voice. For example, a teacher can apply for a WeChat public platform as a learning platform for the $\mathrm{C}$ programming curriculum, and automatically push relevant learning content to students in graphic or micro-video format, communicate in message dialog text, conduct micro-exams, micro-recruitment, and so on. This is a way that students are happy to accept and allow them to use debris to learn.

\section{Conclusion}

In this paper, the characteristics of M-learning, curriculum design principles and M-learning methods were discussed in combination with programming courses. Mobile learning prolongs class time, and learners are no longer bound by time and space. As long as they have the enthusiasm and desire to learn, they can move and learn as they like. Mobile learning improves the efficiency of curriculum teaching and is an effective use of fragmentation time. However, as an informal learning method, mobile learning not only considers learners' knowledge level, cognitive ability, learning style, personal interest, etc., but also learners are influenced by their situational factors. Therefore, there are still many things worthy of further study in mobile teaching design.

\section{References}

[1] Li Lijie, Research on Application of Mobile Learning in Higher Vocational Education, University Education, (2015) No.2, p. 53-54, 77.

[2] Ye Rong, Mobile Learning in English Autonomous Learning, Journal of Sichuan College of Education, Vol. 27 (2011) No.10, p.88-91.

[3] FENG Xiu-hong, Research on the Principle of Adult English Mobile Resources Development from the Perspective of U-Learning, Journal of Jiangsu Institute of Commerce, (2017) No.6, p.86-88.

[4] Huang Ronghuai, Wang Xiaochen, Li Yushun, Towards a Theory of Mobile Learning Activity Design, Journal of Distance Education, (2009) No.1, p.3-7.

[5] Information on http://www.tech.net.cn/edu/500.shtml.

[6] JIANG Libing, CHEN Youqing,The Construct and Apply of "Micro-lecture" Design Model for Deep Learning, Modern Distance Education, (2016) No.3, p.34-40.

[7] FAN Wenxiang, MA Yan, LI Kai, QIU Bingfa, A Practical Study in the Flipped Classroom Based on WeChat under Environment of M-learning, Open Education Research, Vol. 21 (2015) No.3, p.90-97. 